\title{
Dirofilariosis in Slovakia - a new endemic area in Central Europe
}

\author{
M. MITERPÁKOVÁ, D. ANTOLOVÁ, Z. HURNÍKOVÁ, P. DUBINSKÝ \\ Parasitological Institute of the Slovak Academy of Sciences, \\ Hlinkova 3, 04001 Košice, Slovak Republic, E-mail: miterpak@saske.sk
}

\begin{abstract}
Summary
The first systematic research on canine dirofilariosis in Slovakia started in February 2007. In total 287 dogs of various age, sex, breeds, and utilization from southern Slovakia were examined within the study until September 2007. Microfilariaemia was detected in 99 (34.5\%) blood samples. Histochemical staining and PCR approach were used for Dirofilaria species identification. Dirofilaria repens was confirmed in all infected dogs; it occurred in $92(32.1 \%)$ dogs as a single infection and in $6(2.1 \%)$ dogs in mixed infection with Dirofilaria immitis. For the first time both species were detected in Eastern Slovakia. Outdoor keeping and age higher 3 years become evident as important risk factors. Male individuals and dogs with long hair were significantly more frequently infected when compared with females and short hair breeds.

The present study revealed the occurrence of highly endemic area of dirofilariosis in Slovakia and certified that climatic conditions in the country are favourable for development of the parasite and for further spread of this zoonotic infection.
\end{abstract}

Keywords: microfilaria; Dirofilaria repens; Dirofilaria immitis; dogs; Slovakia

\section{Introduction}

Climatic changes and in particular global warming, repeated vast floods resulting in increased abundance of mosquitoes, together with increase of pets' movement are considered to be main risk factors of all vector-borne infections (including filarioids) spreading across Europe. At present, dirofilariosis is regarded as arthropod-borne disease with fastest spread and represents high infection risk for both animals and humans.

Due to the pathological effect on dogs and considering their zoonotic potential two species of filarioid nematodes, Dirofilaria immitis, the etiological agent of pulmonary dirofilariosis and Dirofilaria repens, a parasite of subcutaneous tissues are of special interest in Europe.

Life cycle of Dirofilaria spp. involves dogs, cats and other carnivores as definitive hosts and different genera and species of mosquitoes as intermediate hosts and vectors. $D$. immitis adults are primarily found in pulmonary arteries and right heart of carnivores, D. repens in subcutaneous tissues. Following mating, viviparous females lay microfilariae into the blood circulation. Newborns are ingested by a female mosquito through the blood meal. Ingested microfilariae migrate to the Malpighian tubules of insects and moult into second and third larval stages. Environmental temperatures higher than $14{ }^{\circ} \mathrm{C}$ is required for maturation of infective larvae (Fortin \& Slocombe, 1981). Larval development in the mosquito takes $8-10$ days at $28-30{ }^{\circ} \mathrm{C}, 11-$ 12 days at $24{ }^{\circ} \mathrm{C}$ and $16-20$ days at $22{ }^{\circ} \mathrm{C}$ (Cancrini et al., 1988). Infective L3 larvae migrate to the mouthparts of the mosquito and during a later blood meal on an appropriate host enter the bite wound and penetrate local connective tissues. In the subcutis, L3 larvae moult to the next L4 and preadult L5 stages. Juvenile worms migrate to the pulmonary arteries (D. immitis) or stay in subcutis $(D$. repens). Production of microfilariae by female worms begins approximately 6 and half months after infection. Humans are involved to the life cycle as accidental hosts infected by the bite of mosquito harboring infective L3 larvae (Webber \& Hawking, 1955; Anderson, 2000).

In recent years, several epidemiological surveys of canine dirofilariosis have been carried out in Europe. The largest hyperendemic area has been confirmed along the Po River Valley in northern Italy (Genchi et al., 2005). Increase of prevalence and new endemic foci have been ascertained in northeastern and central regions of Italy (Poglayen et al., 1996; Magi et al., 1989), in Sardinia (Scala et al., 2004) and in eastern European countries as Serbia, Croatia (Genchi et al., 2005) and Bulgaria (Georgieva et al., 2001). In recent years autochthonous cases of infection are detected 
more frequently also in previously Dirofilaria - free countries; e. g. in Czech Republic (Svobodová et al., 2007; Dobešová et al., 2007) and Hungary (Fók et al., 2007).

In the territory of the Slovak Republic, canine dirofilariosis was for the first time detected in 2005 in 12 dogs from the Bratislava and Komárno regions in southwestern parts of the country (Svobodová et al., 2005). In 2007 also the first autochthonous case of human dirofilariosis was confirmed (Jallili et al., 2007).

The aim of our study was to perform first detailed epidemiological survey of canine dirofilariosis in Slovakia, to determine a parasite extension and to estimate real prevalence rate among dogs regions at risk.

\section{Material and Methods}

\section{Study area}

The study was carried out in two geographically outlying areas (Figure 1):

I. Southwestern part of Slovakia (The Borská Lowland and Danubian Lowland). Danubian Lowland extends in southern part of the country bordering Hungary and includes territory between Bratislava and Levice districts. The Borská Lowland is in the southwestern part of Slovakia, between the Small Carpathians Mts. and The Morava River, the fluvial boundary between neighbouring Czech Republic and Austria.

II. Southeastern part of Slovakia - Eastern Slovak Lowland that bounds to Ukraine in the east and Hungary in the south. The Bodrog River Basin and lowland protected landscape area Latorica are the dominant features of the region.

Both study regions are the warmest parts of country with mean annual air temperature over $+10^{\circ} \mathrm{C}$ and are characterized by periodic floods in the river systems.

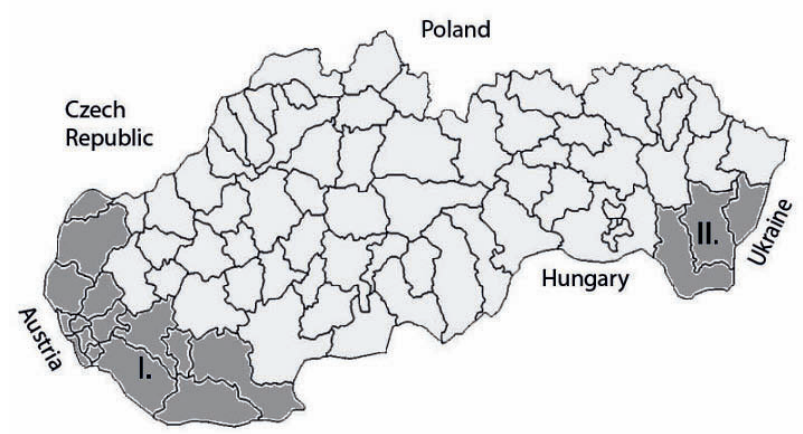

Fig. 1. Studied area (I. Borská and Danubian Lowlands; II. Eastern Slovak Lowland)

\section{Sample collection}

The sample collection was in cooperation with several veterinary practices in the southwestern region and southeastern part of the country. All the veterinarians were asked to choose dogs randomly and to fill in a questionnaire with information on dog (age, gender, breed, hair length, utilization, stay abroad, clinical signs, and locality of residence).
Blood samples from a total of 287 dogs (257 from the Southwestern region and 30 from the Southeastern part) were collected between February and September 2007. About $4 \mathrm{ml}$ of whole blood was drawn from cephalic vein of dogs. Three milliliters of blood were collected in sodium citrate tubes and $1 \mathrm{ml}$ was mixed with $9 \mathrm{ml}$ of $2 \%$ buffered formalin in $12 \mathrm{ml}$ tubes. The collecting tubes were stored at $4{ }^{\circ} \mathrm{C}$ and send to our laboratory for analysis coupled with completed questionnaires.

\section{Methods}

Blood and $2 \%$ formalin mixture was centrifuged (5 min, $1500 \mathrm{rpm}$ ), the supernatant was decanted and sediment was mixed with $0.5 \%$ methylene blue stain. Stained sediment was examined under a microscope at 400x magnification for the presence of microfilariae (Knott, 1939). For species determination the positive samples were analyzed using histochemical staining based on the different somatic distribution of acid phosphatase activity using commercial kit test (Leucognost-SP ${ }^{\circledR}$, Merck, Darmstadt, Germany) according to Peribánez et al. (2001).

All positive samples were additionally examined using a PCR approach for species confirmation. DNA was extracted from $200 \mu \mathrm{l}$ of canine citrate-treated blood using DNeasy Blood and Tissue Kit (Qiagen). PCR reaction for the amplification of the cytochrome oxidase subunit 1 (CO1) gene was performed in a final volume of $25 \mu \mathrm{l}$ using specific Dirofilaria immitis and Dirofilaria repens pairs of primers (Rishniw et al., 2006). All PCR reactions consisted of a denaturing step at $94{ }^{\circ} \mathrm{C}$ for $2 \mathrm{~min}$ and 35 cycles of denaturing $30 \mathrm{~s}$ at $94{ }^{\circ} \mathrm{C}$, annealing $30 \mathrm{~s}$ at $57^{\circ} \mathrm{C}$ and extension $\left(30 \mathrm{~s}\right.$ at $\left.72{ }^{\circ} \mathrm{C}\right)$ with final extension $7 \mathrm{~min}$ at $72{ }^{\circ} \mathrm{C}$. The PCR products were visualized on a $1.5 \%$ agarose gel.

\section{Data analysis}

The prevalence of canine microfilariaemia was calculated in the dog population. Logistic linear regression analysis at $95 \%$ confidence level was performed and odds ratio (OR) was calculated in order to estimate the epidemiological measure of association between variables included to the study (age, gender, hair length, utilization) and risk of dirofilariosis. All statistical analyses were conducted using STATISTICA 6 Base (StatSoft, Inc., 2001).

\section{Results}

Microfilariae were detected in $99(34.5 \%)$ of the 287 dogs examined. Canine filarioidosis was diagnosed in 83 (32.9\%) of 257 dogs from the Southwestern part of Slovakia (The Borská and Danubian Lowlands) and in 16 (53.3\%) of 30 dogs from the Eastern Slovak Lowland.

Histochemical staining and DNA analyses confirmed the presence of Dirofilaria repens in all infected dogs. A total of $92(32.1 \%)$ dogs harbored single infection by this species and in $6(2.1 \%)$ dogs the mixed infection with Dirofilaria immitis was detected (4 animals from area I. and 2 from area II.). No single infection caused by $D$. immitis 
was found.

The relationship between selected epidemiological factors and Dirofilaria spp. prevalence was evaluated. All data are summarized in Table 1. The utilization of dogs represents a significant risk factor for filarioids infection. Out of 90 companion, 32 watch and guard, 75 hunting and 90 police dogs included into the survey, a low prevalence of dirofilariosis among companion dogs $(7.8 \%)$ was found. On the contrary, in groups of hunting, guard and police dogs the prevalence rates were significantly higher $(40.0 \%, 50.0 \%$ and $51.1 \%$, respectively; $P=0.0141$ ).

The age impact of individual dogs on the risk of infection is also regarded as relevant. Out of 246 dogs, 110 were younger or equal than 3 years and 136 were older than 3 years. Canine dirofilariosis was more often detected in animals aged over 3 years $(38.2 \%)$ when compared with younger dogs $(18.2 \%)(\mathrm{OR}=2.786, \mathrm{CI}=1.536-5.052, P$ $=0.0003$ ).

Our study also revealed that the male gender $(\mathrm{OR}=1.496$, $\mathrm{CI}=0.910-2.461, P=0.0284)$ and long hair $(\mathrm{OR}=$ $1.456, \mathrm{CI}=0.876-2.419, P=0.0358$ ) were risk factors for filarioid infection in dogs.

Table 1. Data obtained within parasitological examination of dogs for Dirofilaria spp. infection. Logistic regression model risk of canine dirofilariosis in Slovakia

\begin{tabular}{|c|c|c|c|c|c|c|}
\hline Variable & $\begin{array}{c}\text { Numbers of } \\
\text { dogs examined }\end{array}$ & Positive dogs & $\begin{array}{c}\text { Prevalence } \\
(\%)\end{array}$ & $\begin{array}{c}\text { OR } \\
\text { (Odds ratio) } \\
\end{array}$ & $\begin{array}{c}95 \% \text { CI } \\
\text { (confidence interval) }\end{array}$ & P-value \\
\hline \multicolumn{7}{|l|}{ Utilization $(n=287)$} \\
\hline Companion dogs & 90 & 7 & 7.8 & 0.096 & $0.042-0.219$ & \multirow{4}{*}{0.0141} \\
\hline Guard dogs & 32 & 16 & 50.0 & 2.072 & $0.988-4.347$ & \\
\hline Hunting dogs & 75 & 30 & 40.0 & 1.382 & $0.802-2.381$ & \\
\hline Police dogs & 90 & 46 & 51.1 & 2.841 & $1.689-4.776$ & \\
\hline \multicolumn{7}{|l|}{ Age $(n=246)$} \\
\hline$\leq 3$ years & 110 & 20 & 18.2 & 0.359 & $0.198-0.651$ & \multirow[b]{2}{*}{0.0003} \\
\hline$>3$ years & 136 & 52 & 38.2 & 2.786 & $1.536-5.052$ & \\
\hline \multicolumn{7}{|l|}{ Gender $(n=281)$} \\
\hline Male & 151 & 59 & 39.1 & 1.496 & $0.910-2.461$ & \multirow[b]{2}{*}{0.0284} \\
\hline Female & 130 & 39 & 30.0 & 0.668 & $0.406-1.10$ & \\
\hline \multicolumn{7}{|l|}{ Hair length $(n=266)$} \\
\hline Short & 121 & 38 & 31.4 & 0.687 & $0.413-1.141$ & \\
\hline Long & 145 & 58 & 40.0 & 1.456 & $0.876-2.419$ & 0.0358 \\
\hline
\end{tabular}

\section{Discussion}

Previously dirofilariosis was considered a rare and uncommon disease in Slovakia and veterinarians did not attach importance to it. The results of this survey have demonstrated that cutaneous dirofilariosis is widespread among dogs in southern part of the country with mean prevalence rate of $34.5 \%$. Our research has confirmed the occurrence of autochthonous canine dirofilariosis in the Danubian Lowland in Southwestern Slovakia, where the infection was first detected in 2005 (Svobodová et al., 2005) and also the presence of the parasite in Southeastern Slovakia. Autochthonous source of infection has been confirmed almost in all infected dogs. Seven of them spent some time abroad (Austria, Croatia, Czech Republic, Hungary, Poland and Iran). Any health state alteration become evident only in 4 positive dogs (in 3 cases dermal changes and in 1 case malaise and lack of appetite were observed).

Our findings also indicate that Dirofilaria repens is the predominant species in Slovakia with all individuals infected by this taxa. However, Dirofilaria immitis was also detected in 6 dogs (3 hunting and 3 police dogs) in coinfection with $D$. repens. The less frequent presence of the latter species can be explained by the findings of Genchi et al. (1995) who, studying the interaction between two species of Dirofilaria in dogs in southern Italy, pointed out the phenomenon of impeding the spread of $D$. immitis in areas where $D$. repens is present in high prevalence rate.

The statistical analysis revealed that utilization and age of dogs are particularly important factors influencing occurrence of dirofilariosis. Police dogs, guard dogs and hunting dogs were unambiguously more often found to be infected when compared with companion dogs. The main reason of the higher infection prevalence in these dog groups should be substantiated by the fact that these dogs are kept outdoors and thus the probability of being attacked by mosquitoes is higher.
Our results showed that old age is also an important risk factor for filarioid infection. The possible explanation for this fact is longer exposure of older animals to the mosquitoes as proven by Montoya et al. (1998), Cringoli et al. (2001) and others.

The present study points out that male gender and longhaired breeds represent a higher relative risk of dirofilariosis as against females and short-haired dogs. The explanation of this interference needs more effort for sound interpretation. Moreover, the results could be impacted by the fact that major proportion of infected police and guard dogs was represented by male individuals of pure bred German Shepherd dogs.

Heartworm disease caused by $D$. immitis in particular, is serious chronic disease affecting the physiological condition and survival of the dogs. In addition, the treatment is 
complicated and pharmacotherapy is ambiguous due to a high risk of thromboembolic complications and heart failure especially in dogs under intensive working loads. Thus, the high infection rates in police and hunting dogs found out in our study represent a serious problem.

With respect to zoonotic potential of both species detected in the present survey, proper prophylactic arrangements against Dirofilaria spp. are to be introduced in Slovakia. Nowadays the only practicable preventive measure for human is the reduction of filarioid infection in dog population, elimination of vectors and using repellents.

Further epidemiological research is aimed to acquire more profound information on extent of the infection in other regions of Slovakia and to evaluate the role of different environmental factors (humidity, rainfall, land-cover) and mosquito species in the spread of the infection.

\section{Acknowledgement}

The investigation was supported by the Science Grant Agency VEGA 2/7186/27.

\section{References}

ANDERSON, R. C. (2000): Nematode parasites of vertebrates, their development and transmission. $2^{\text {nd }}$ Edition, CABI Publishing, Wallingford, UK, $650 \mathrm{p}$.

CAncrini, G., Sun Yanchang, Della Torre, A., ColuzzI, M. (1988): Influenza della temperatura sullo sviluppo larvale di Dirofilaria repens in diverse specie di zanzare. Parassitologia, 30: 38

CRingoli, G., Rinaldi, L., Veneziano, V., CAPElli, G. (2001): Prevalence survey and risk analysis of filariosis in dogs from the Mt. Vesuvius area of southern Italy. Vet. Parasitol., 102: 243 - 252

DobešovÁ, R., SvobodovÁ, Z., SvobodovÁ, V. (2007): Dirofilariosis in dogs - the actual situation in the Czech Republic. In GENCHI, C., RINALDI, L., CRINGOLI, G. (Eds.): Mappe Parassitologie - Dirofilaria immitis and Dirofilaria repens in dog and cat and human infection, 8:198

Fortin, J. F., Slocombe, J. O. D. (1981): Temperature requirements for the development of Dirofilaria immitis in Aedes triseriatus and Ae. vexans. Mosq. News, 41: 625 - 633 FoK, É., Kiss, G., MAJOROS, G., JACsÓ, O., FARKAS, R., GYURKOVSZKY, M. (2007): Preliminary results of an epidemiological survey on dirofilariosis of dogs and cats in Hungary. In GenchI, C., RinAldi, L., CRINGOLI, G. (Eds.): Mappe Parassitologie - Dirofilaria immitis and Dirofilaria repens in dog and cat and human infection, 8: 195

Genchi, C., Solari Basano, G., Bandi, C., Di Sacco, B., Venco, L., Vezzoni, A., CANCRINI, G. (1995): Factors influencing the spread of heartworms in Italy: interaction between Dirofilaria immitis and Dirofilaria repens. Proceedings of Heartworm Symposium '95. American Heartworm Society, Baravia, IL., $65-71$

Genchi, C., Rinaldi, L., Cascone, C., Mortarino, M., CRINGOLI, G. (2005): Is heartworm disease really spreading in Europe? Vet. Parasitol., 133 (2): 137 - 148

Georgieva, D., Kirkova, Z., Ivanov, A. (2001): A study on the incidence and diagnostic of dirofilariosis (heartworm disease) in carnivores. Bulgarian J. Vet. Med., 4: 231 - 236

Jallili, N., KobzovÁ, D., NovÁK, I., Dubinský, P., BABÁL, P. (2007): The first case of human dirofilariosis in Slovakia (in Slovak with English abstract). Acta Tropica, 5: $75-78$

KNOTT, J. (1939): A method for making microfilarial surveys on day blood. Trans. R. Soc. Trop. Med. Hyg., 33: 191 Magi, M., Marroncini, A., SAssetti, M. (1989): Distribution of canine filariasis in Tuscany. Sel. Vet., 30: $1185-$ 1187

Montoya, J. A., Morales, M., Ferrer, O., Molina, J. M., CorberA, J. A. (1998): The prevalence of Dirofilaria immitis in Gran Canaria, Canary Islands, Spain (1994 1996). Vet. Parasitol., 75: 221 - 226

Peribanez, M. A., Lucientes, J., Arce, S., Morales, M., Castillo, J. A., Gracia, M. J. (2001): Histochemical differentiation of Dirofilaria immitis, Dirofilaria repens and Acanthocheilonema dracunculoides microfilariae by staining with a commercial kit, Leucognost-SP®. Vet. Parasitol., 102: 173 - 175

Poglayen, G., Martini, M., Bomben, L., Roda, R. (1996): An update of the occurrence of canine heartworm disease in northern Italy. Vet. Res. Commun., 20: 303 - 307 Rishniw, M., BARR, S. C., Simpson, K. W., Frongillo, M., Franz, M., Dominquez Alpizar, J. L. (2006): Discrimination between six species of canine microfilariae by a single polymerase chain reaction. Vet. Parasitol., 135 (3): $303-314$

Scala, A., Atzori, F., Varcasia, A., GripPa, G., GenCHI, C. (2004): Filariosis in Sardinia : epidemiological updating (1998-2004). Atti SISVET, 58: 120 - 122

STATSOFT, INC: STATISTICA, v. 6, 2001, http://www.stat soft.com

Svobodová, Z., Svobodová, V., Genchi, C. (2007): Dirofilaria repens infection in dogs in the Czech Republic. In Genchi, C., Rinaldi, L., CRIngoli, G. (Eds.): Mappe Parassitologie - Dirofilaria immitis and Dirofilaria repens in dog and cat and human infection, 8: 199

Svobodová, V., Svobodová, Z., BeladičovÁ, V., VAlENTOVÁ, D. (2005): First case of canine dirofilariosis in Slovakia: a case report. Vet. Med. Czech., 50 (11): 510 - 512

WebBer, W. A. F., Hawking, F. (1955): Experimental maintenance of Dirofilaria repens and D. immitis in dogs. Exp. Parasitol., 4: 143 - 164 